Article

\title{
Studies Towards the Development of a Novel, Screen-Printed Carbon-Based, Biosensor for the Measurement of Polyunsaturated Fatty Acids
}

\author{
Amy Smart ${ }^{(D)}$, Adrian Crew ${ }^{(D)}$, Olena Doran and John P. Hart *(i) \\ Centre for Research in Biosciences, Faculty of Health and Applied Sciences, Frenchay Campus, \\ University of the West of England, Coldharbour Lane, Bristol BS16 1QY, UK; amy.smart@uwe.ac.uk (A.S.); \\ Adrian.crew@uwe.ac.uk (A.C.); olena.doran@uwe.ac.uk (O.D.) \\ * Correspondence: John.hart@uwe.ac.uk
}

Received: 19 October 2020; Accepted: 30 October 2020; Published: 3 November 2020

check for updates

Featured Application: Measurement of polyunsaturated fatty acids for food safety and quality.

\begin{abstract}
This paper describes the design, development and characterisation of an electrochemical biosensor for the measurement of linoleic and $\alpha$-linolenic acid, as representative free polyunsaturated fatty acids (PUFAs), that may be implicated in food safety and food quality. Initial cyclic voltammetric studies were performed with solutions that contained enzyme-generated hydroperoxides of the two PUFAs. These were examined with plain screen-printed carbon electrodes (SPCEs) and screen-printed carbon electrodes containing the electrocatalyst cobalt phthalocyanine (CoPC). The electrocatalytic oxidation peaks obtained with the latter occurred at potentials about $300 \mathrm{mV}$ lower than the those obtained by direct oxidation with the plain SPCEs and were better defined; as these attributes would lead to better selectivity and sensitivity for fatty acid determinations, the CoPC-SPCEs were used in the fabrication of amperometric biosensors. The enzyme lipoxygenase (LOX) was immobilised on the surface of these devices using the crosslinking agent glutaraldehyde. These biosensors were optimised for the measurement of linoleic and $\alpha$-linolenic acid using amperometry in stirred solution; the optimum conditions were deduced by studying the effect of enzyme loading, $\mathrm{pH}$ and temperature on the amperometric responses. These responses were examined over the concentration range 2.0 to $20 \mu \mathrm{M}$ and the results indicated that the following conditions were optimal: LOX loading 15 units; $\mathrm{pH}$ 8.0; temperature $37^{\circ} \mathrm{C}$. Low concentration calibration studies were performed with the two PUFAs and it was shown that the steady state currents were linear between 0.2 and $10 \mu \mathrm{M}$ for linoleic acid and 0.2 and $10 \mu \mathrm{M}$ for $\alpha$-linolenic acid; the detection limits were 24 and $100 \mathrm{nM}$, respectively. The precision (coefficient of variation, $n=6$ ) was $5.3 \%$ for $\alpha$-linoleic acid and $3.3 \%$ for linoleic acid, which were calculated from the steady state current following additions $(n=6)$ of $0.2 \mu \mathrm{M}$ PUFA. These results demonstrate that the novel amperometric biosensor holds promise for determining whether foods contain acceptable levels of free fatty acids.
\end{abstract}

Keywords: food safety; food quality; amperometric biosensor; cyclic voltammetry; screen-printed carbon electrode; PUFA; free fatty acid

\section{Introduction}

Fatty acids play an important role in food safety and food quality. Dietary polyunsaturated fatty acids (PUFAs) has been found to have a number of health benefits including a positive effect on cardiovascular health [1]. n-3 PUFAs, abundant in oily fish, and n-6 PUFAs, found in grains are, of particular interest as they are associated with positive effects on a wider range of human health, including anti-inflammatory effect and neurological health [2]. 
PUFAs are mostly found as triglycerides. Triglycerides are prone to hydrolysis, producing free fatty acids (FFAs). The PUFA FFAs are unstable and can degrade further into hydoperoxides and short chain free fatty acids, causing rancidity, unpleasant taste and smell [3]. As well as affecting the quality, the presence of high levels of FFAs have implications for food safety; high levels of FFAs in different food products can indicate issues with storage time, temperature, moisture content, mould or infestation [4-9]. Some examples are described below.

According to Wiking et al., a rancid, bitter or 'off' flavour in dairy is attributed to short-chain FFAs [5]. The concentration of medium to long chain FFAs (which are most abundant) is correlated with the concentration of short-chain FFAs, so measuring these is an indirect measurement of rancid flavour.

Wiking et al. found that the sensory threshold of rancid flavour was $1.95 \mathrm{mmol}$ of FFA per $100 \mathrm{~g}$ of fat [5]. Santos et al. [6] estimated a sensory threshold between 1.58 and $1.76 \mathrm{mmol}$ of FFA per $100 \mathrm{~g}$ of fat in $2 \%$ fat milk, and Gonzalez-Cordova et al. correlated FFAs levels of farm milk to sensory perception and only one sample with a FFA content above $2 \mathrm{mmol}$ per $100 \mathrm{~g}$ of fat was considered rancid [7]. Altogether, these studies suggest the acceptable value of FFAs to be below 2 mmol per $100 \mathrm{~g}$ of fat.

Extra virgin olive oil, which is a valuable gourmet product, may not have an FFA content of more than 1\%, according to the European Union (EEC No 796/2002) [8]. Other olive oils for consumption have a limit of $3.3 \%$, and oils with a higher FFA content are referred to as lampante and must be refined before consumption [8].

A high FFA content in olive oil is attributed to anomalies during the process of biosynthesis, microbial activities and environmental conditions. Infestation by the olive fly (Bactrocera oleae) is a major cause of high FFA content in olives, bruised olives that have fallen from the trees coupled with prolonged storage causes lipolysis and FFAs, and finally, a badly conducted extraction process also decreases oil quality [8]. In the European Union, the official method for determining the FFA content of olive oil is by dissolving the oil in ethyl ether and ethanol and titrating it against an alkali using a phenolphthalein indicator [8].

The level of FFAs in the fat of cocoa beans is a measure of the rancidity of the cocoa. High levels of FFA in cocoa are not acceptable, and in Europe, manufacturers may not legally sell cocoa butter containing over $1.75 \%$ FFA [9]. The presence of large amounts of FFAs in the fat of cocoa beans tends to indicate other problems with the cocoa; for example, either it has been wet for too long and/or it has a high percentage of mould, and thus is unsafe for human consumption.

Developing effective technologies for the detection and quantification of FFAs is one of the challenges of the international food industry. Fatty acids may be analysed by traditional chromatographic methods; however, these are expensive, time consuming and must be performed in a lab by skilled personnel. In contrast, the novel biosensor approach based on screen-printing carbon electrodes has many benefits-they can be manufactured in a wide-range of geometries at low cost as carbon is an inexpensive material, therefore they can be considered as disposable; these characteristics lead to rapid, portable and user-friendly devices [10]. Electrocatalysts may be incorporated into the carbon ink of sensors where they act as electron shuttles for electrochemical reactions, thus increase the sensor sensitivity. Adding a selective enzyme into (bio)sensors can enhance specificity. An appropriate enzyme for PUFAs is lipoxygenase (LOX), which catalyses the oxidation of PUFAs.

This paper will discuss studies towards the development of a novel electrochemical (bio)sensor using SPCEs as a platform for their construction and their potential for application in food industry for rapid analysis of PUFAs content in relation to food quality and safety.

Previous work by our group has demonstrated the feasibility of using SPCE sensors and (bio)sensors for the analysis of target analytes in challenging matrices for agri-food applications (progesterone in milk [11], monosodium glutamate in stock cubes [12], fructose in fruit juice [13], organophosphates in cereals and raw produce [14], boar taint in pork [15], thiamine in soft drinks [16]). 


\section{Materials and Methods}

\subsection{Instrumentation}

All voltammetric and amperometric measurements were carried out with a $\mu$ Autolab III potentiostat interfaced to a PC for data acquisition via NOVA v2.0 (Metrohm, Barendrecht, The Netherlands) or an AMEL Model 466 polarographic analyser attached to an ABB Gorez SE120 chart recorder. An in-house low pass filter (time constant $22 \mathrm{~s}$ ) was incorporated between the potentiostat and the chart recorder to substantially reduce stirrer noise. SPCEs are commercially available and were supplied by Gwent Electronic Materials Ltd. (Pontypool, UK). For CoPC-SPCEs, the working electrode was fabricated using a carbon-based ink with CoPC (C2030408P3) and the reference electrode was fabricated using an $\mathrm{Ag} / \mathrm{AgCl}$ ink (C2130809D5). The working electrode area ( $3 \mathrm{~mm} \times 3 \mathrm{~mm}$ ) was defined using electrical insulation tape. For plain SPCEs, the working electrode was fabricated using a carbon ink (C2030519P4), and the reference electrode was fabricated using an $\mathrm{Ag} / \mathrm{AgCl}$ ink as before. The working electrode area was defined as before. All $\mathrm{pH}$ measurements were carried out with a Testo 205 (Testo Limited, Alton, Hampshire UK) pH meter. Solutions were stirred using a colour squid (IKA, Tunbridge Wells, UK) and warmed using a HAAKE P5 water bath (Thermo Scientific, Loughborough, UK). Surface morphology and composition of the working electrode were analysed using a Quanta FEG 650 scanning electron microscope (FEI, Hillsboro, OR, USA) $(4000 \times$ magnification; samples were gold-coated).

\subsection{Chemicals and Reagents}

All chemicals were purchased from Sigma Aldrich (Dorset, UK). Deionised water was obtained from a Purite RO200 Stillplus HP System (Oxon, UK). Stock solutions of monosodium, disodium and trisodium orthophosphate were prepared at a concentration of $0.2 \mathrm{M}$ by dissolving the appropriate mass in deionised water; these were then titrated to achieve the desired $\mathrm{pH}$ and diluted in the cell to achieve a working concentration of $0.1 \mathrm{M}$. Sodium chloride was prepared to a concentration of $1.0 \mathrm{M}$ by dissolving the appropriate mass in deionised water; this was diluted in the cell, giving a final concentration of $0.1 \mathrm{M}$. LOX enzyme was aliquotted and diluted with $0.1 \mathrm{M} \mathrm{pH} 7.0$ phosphate buffer saline to give the desired number of enzyme units. A 50\% glutaraldehyde stock solution was also diluted with $0.1 \mathrm{M} \mathrm{pH} 7.0$ phosphate buffer saline to give a $0.01 \%$ solution. Stock solutions of $\alpha$-linolenic acid and linoleic acid, were prepared in methanol at concentrations of 10 and $1 \mathrm{mM}$ respectively.

\subsection{Biosensor Fabrication and Storage}

The CoPC-SPCE working electrodes were drop-coated with $10 \mu \mathrm{L}$ of LOX solution (to give 15 , 150,1500 or 15,000 units per sensor). The biosensors were dried overnight using a desiccator under vacuum. The enzyme was then immobilised to the electrode surface by drop-coating $10 \mu \mathrm{L}$ of a $0.01 \%$ glutaraldehyde solution, which was again dried overnight using a desiccator under vacuum. Biosensors were stored in airtight containers at $4{ }^{\circ} \mathrm{C}$ for up to 12 months.

\subsection{Voltammetric and Amperometric Procedures}

Cyclic voltammetry was used to deduce electrochemical behaviour of the fatty acids and enzyme at a plain SPCE and a CoPC-SPCE. The scan was performed over a voltage window of -1 to $+1.5 \mathrm{~V}$ vs. $\mathrm{Ag} / \mathrm{AgCl}$. The cell contained $10 \mathrm{~mL}$ of $0.1 \mathrm{M}$ PBS and $0.1 \mathrm{mM}$ of fatty acid (either linoleic acid or $\alpha$-linolenic acid), as well as 5000 units $/ \mathrm{mL}$ of LOX, and was warmed to $37^{\circ} \mathrm{C}$.

In order to deduce the optimum operating potential for amperometric measurements in stirred solution, a hydrodynamic voltammogram was constructed over the range +0.0 to $+1.2 \mathrm{~V} \mathrm{vs}$. $\mathrm{Ag} / \mathrm{AgCl}$ using $100 \mu \mathrm{M}$ of $\alpha$-linolenic acid, in $10 \mathrm{~mL} 0.1 \mathrm{M} \mathrm{pH} 7$ phosphate buffer saline, warmed to $37^{\circ} \mathrm{C}$. This was repeated with linoleic acid.

To optimise the number of enzyme units, calibration studies were carried out using biosensors fabricated with four different loadings of LOX. The potential was held at $+0.5 \mathrm{~V}$, and the solution was 
stirred at $250 \mathrm{rpm}$ and warmed to $37^{\circ} \mathrm{C}$. $\alpha$-Linolenic acid was pipetted into a cell containing $10 \mathrm{~mL}$ $0.1 \mathrm{M} \mathrm{pH} 7.0$ phosphate buffer saline at regular intervals; a total of ten $20 \mu \mathrm{L}$ additions of $10 \mathrm{mM}$ stock were made (between 20 and $200 \mu \mathrm{g} / \mathrm{mL}$ ).

The optimally fabricated biosensor was used to perform calibration studies to optimise $\mathrm{pH}$. Ten $2 \mu \mathrm{L}$ additions of $10 \mathrm{mM} \alpha$-linolenic acid were made into a cell containing $10 \mathrm{~mL} 0.1 \mathrm{M}$ phosphate buffer saline, stirred at $250 \mathrm{rpm}$ at $25^{\circ} \mathrm{C}$. The $\mathrm{pH}$ was $6.0,7.0,8.0$ or 9.0. This was repeated with linoleic acid. The measurement temperature was then optimised; ten $2 \mu \mathrm{L}$ additions of $10 \mathrm{mM} \alpha$-linolenic acid were made into a cell containing $10 \mathrm{~mL}$ pH8 0.1M phosphate buffer saline, stirred at $250 \mathrm{rpm}$ at 25, 30, 37, and $40{ }^{\circ} \mathrm{C}$. This was repeated using linoleic acid.

The optimal conditions were used to perform a low concentration calibration study, using an analogue instrument with a low pass filter to reduce stirrer noise. Ten $2 \mu \mathrm{L}$ aliquots of $1 \mathrm{mM} \alpha$-linolenic acid were added into a cell containing $10 \mathrm{~mL} 0.1 \mathrm{M} \mathrm{pH} 8$ phosphate buffer saline solution, stirred at 250rpm and warmed to $37^{\circ} \mathrm{C}$. This was repeated using linoleic acid.

\section{Results and Discussion}

3.1. Cyclic Voltammetric Studies of Linoleic and $\alpha$-Linolenic Hydroperoxides, Generated Using LOX in Free Solution, Using Plain SPCEs and CoPC-SPCES

Initial studies were performed using cyclic voltammetry to deduce the electrochemical behaviour of the fatty acid hydroperoxides, enzymatically generated by the action of LOX on linoleic and $\alpha$-linolenic acid. Two different types of working electrode were employed, namely a plain screen-printed carbon electrode (SPCE) and a SPCE which had been modified with the electrocatalyst cobalt phthalocyanine (CoPC), the latter is designated a CoPC-SPCE. The two test solutions initially contained either linoleic acid or $\alpha$-linolenic acid, at a concentration of $0.1 \mathrm{mM}$ and $5 \mathrm{~K}$ units $/ \mathrm{mL}$ of the enzyme LOX. Figure 1 , shows the resulting voltammograms obtained for the two types transducers with these solutions, and with a blank solution comprised of $0.1 \mathrm{M}$ phosphate buffer containing $0.1 \mathrm{M} \mathrm{NaCl}$.

Figure 1a (blue) shows the cyclic voltammogram obtained with linoleic hydroperoxide, using a plain SPCE; this exhibits an oxidative current from about $+1 \mathrm{~V}$ that increases rapidly up to $+1.5 \mathrm{~V}$. The blank obtained with this electrode (dotted black) showed a considerably smaller current over the same voltage range. Although this anodic behaviour, resulting from direct oxidation of the hydroperoxide, is potentially analytically useful, the applied potential needed to operate an amperometric biosensor would be rather high. However, as seen in Figure $1 \mathrm{~b}$ (red), when the SPCE is modified with the electrocatalyst cobalt phthalocyanine, the resulting CoPC-SPCE produces a well-defined voltammetric response at a much lower potential (plateau at about $+0.75 \mathrm{~V} \mathrm{vs}$. $\mathrm{Ag} / \mathrm{AgCl}$ ). Consequently, better selectivity would be expected with this working electrode, than with the former.

The cyclic voltammetric behaviour obtained with $\alpha$-linolenic hydroperoxide, with the same two working electrodes, showed similar behaviour (Figure 1c,d) to that found with linoleic hydroperoxide (Figure 1a,b). In this case, the CoPC-SPCE again produced the more analytically useful anodic response.

The anodic responses obtained with the plain SPCEs are considered to result from the direct oxidation of the hydroperoxide functional group at the carbon surface. In the case of linolenic hydroperoxide, one hydroperoxide group is believed to be present at position- 13 of the carbon chain [17], which has a chain length of 18 carbons; the electrode reaction is considered to be that shown in Equation (1):

$$
\mathrm{ROOH} \rightarrow \mathrm{R} \cdot+\mathrm{O}_{2}+\mathrm{H}^{+}+\mathrm{e}^{-} \text {(SPCE surface) }
$$

The free radicals (R.) formed during the reaction may be expected to dimerise.

In the case of linoleic hydroperoxide, there are believed to be two hydroperoxide groups formed at position-9 and position-13 of the 18-carbon chain [17]. If both of these hydroperoxide groups were to undergo electrochemical oxidation at the SPCE surface, the magnitude of the anodic current should be larger than that observed with the linolenic hydroperoxide. If one compares the magnitude of the 
anodic currents at a potential of $+1.5 \mathrm{~V}$ vs. $\mathrm{Ag} / \mathrm{AgCl}$, for these two species shown in Figure 1a,b (both blue voltammograms), this does seem to be the case.

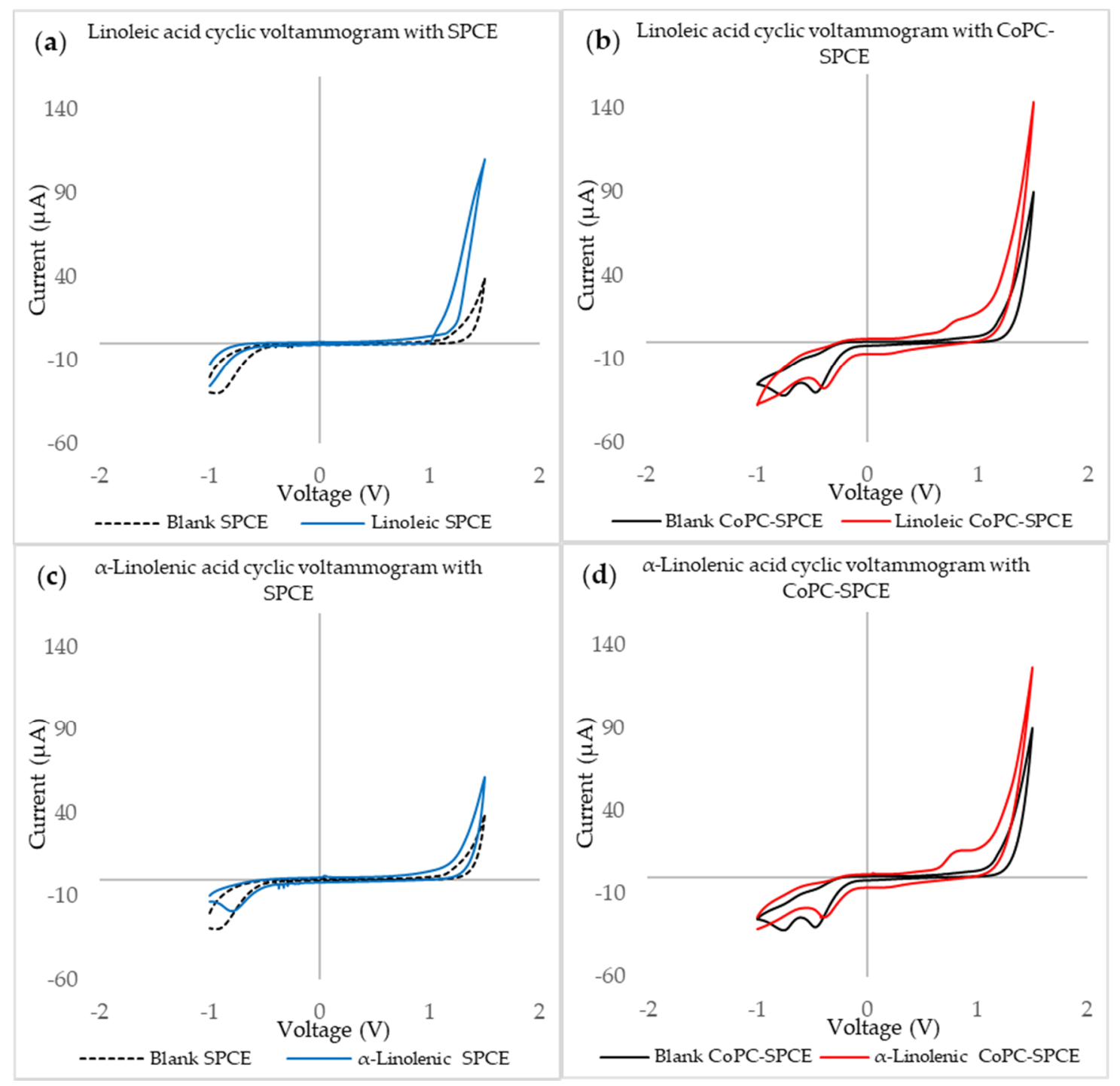

Figure 1. Cyclic voltammograms obtained for: (a) linoleic acid using a plain SPCE with LOX (blue), and blank buffer solution (dashed black); (b) linoleic acid using a CoPC-SPCE with LOX (red), and blank buffer solution (black); (c) $\alpha$-linolenic acid using a plain SPCE with LOX (blue) and a blank buffer solution (dashed black); (d) $\alpha$-linolenic acid using a CoPC-SPCE with LOX (red), and a blank buffer solution (black). SPCE = screen-printed carbon electrode; $\mathrm{CoPC}=$ cobalt phthalocyanine; LOX = lipoxygenase.

The anodic responses obtained with the CoPC-SPCEs are considered to result from the electrocatalytic oxidation of the hydroperoxide groups, which involves redox reactions of the central cobalt ion $\left(\mathrm{Co}^{+} / \mathrm{Co}^{2+}\right)$ of cobalt phthalocyanine; this is discussed more fully in the following section. As mentioned above, the lower oxidation potential obtained with this working electrode offered better selectivity, consequently we decided to explore the possibility of exploiting this device as a platform in the design of an amperometric fatty acid biosensor.

\subsection{Amperometric Fatty Acid Biosensor Design and Characterisation}

As mentioned in the previous section, our cyclic voltammetric studies demonstrated that it should be feasible to fabricate a fatty acid amperometric biosensor, based on a CoPC-SPCE, by immobilising 
LOX onto the electrode surface; a schematic diagram of the biosensor construction is shown in Figure 2. Figure 3 shows a schematic diagram of the sequence of reactions involved in the measurement of the fatty acids. The enzyme LOX is immobilised on to the surface of a CoPC-SPCE by cross-linking with glutaraldehyde. During the biosensor operation, the fatty acid (linoleic or $\alpha$-linolenic acid) from the bulk solution diffuses into the enzyme reaction layer which, in the presence of oxygen, produces the corresponding hydroperoxide (see previous section). This species chemically reduces $\mathrm{Co}^{2+}$ to $\mathrm{Co}^{+}$in the cobalt phthalocyanine molecule, which then undergoes electrochemical oxidation to reform $\mathrm{Co}^{2+}$. These reactions can be considered as the electrocatalytic oxidation of the hydroperoxide species to produce $\mathrm{O}_{2}$, a proton and a free radical (R.). The transfer of one electron from $\mathrm{Co}^{+}$to the electrode surface (oxidation) constitutes the analytical response. This electrochemical response occurs at much lower oxidation potentials than required for the direct oxidation which occurs using a plain SPCE; therefore, better selectivity is achieved when exploiting the electrocatalytic reaction. It should be noted that hydrogen peroxide undergoes electrocatalytic oxidation using a cobalt phthlocyanine based sensor which involves the chemical reduction of $\mathrm{Co}^{2+}$ to $\mathrm{Co}^{+}$followed by electrochemical oxidation of $\mathrm{Co}^{+}$ back to $\mathrm{Co}^{2+}$ (the latter constituting the analytical response) [18], whereas other biomolecules such as cysteine involve the $\mathrm{Co}^{3+}$ to $\mathrm{Co}^{2+}$ redox couple [19]. We believe it is likely the hydroperoxides of $\alpha$-linolenic and linoleic acid would undergo electroctalytic oxidation involving the $\mathrm{Co}^{2+} / \mathrm{Co}^{+}$couple, due to the similarity of their functional groups to hydrogen peroxide and the similarity of their electrocatalytic oxidation potentials [20].

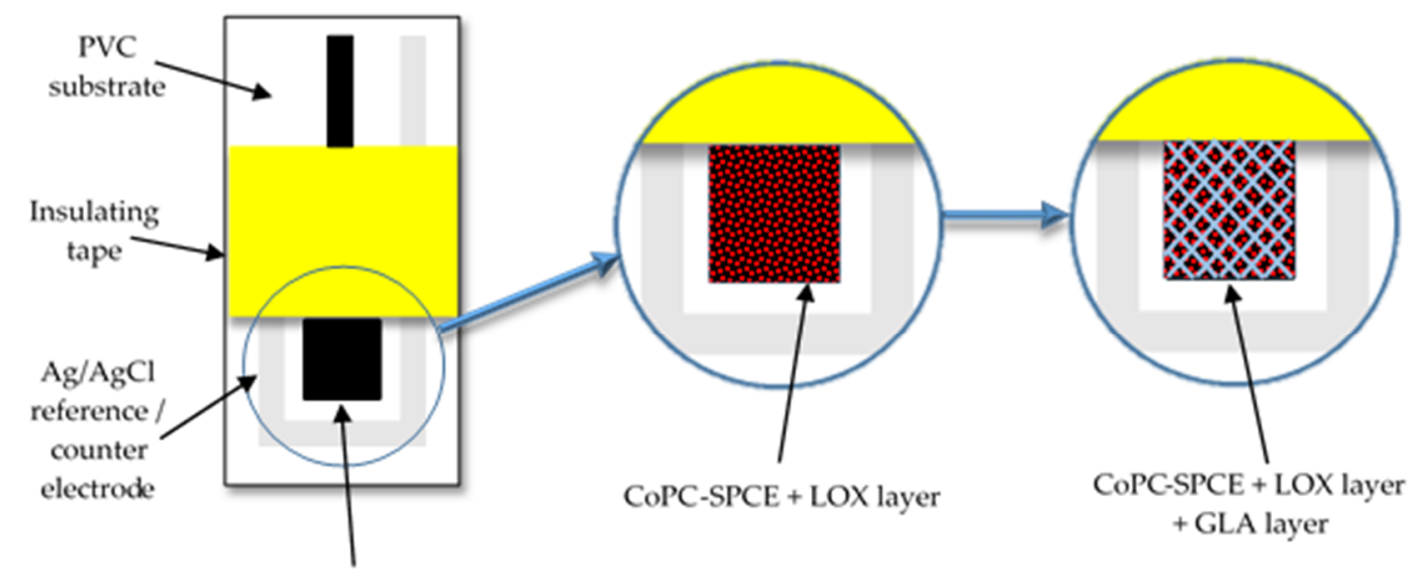

CoPC-SPCE working electrode $(4 \times 4 \mathrm{~mm})$

Figure 2. Schematic showing the sequential deposition of the enzyme and cross-linking agent onto Table 3. Schematic diagram of the amperometric fatty acid biosensor design and the sequence of reactions involved in its operation; SPCE = screen-printed carbon electrode; LOX = lipoxygenase; GLA = glutaraldehyde.

In order to deduce the surface morphology of the biosensor during the modification processes, we employed scanning electron microscopy. Figure 4 shows a series of three SEM images obtained during the construction of the amperometric biosensor: image (i) shows the initial CoPC-SPCE, as can be seen characteristic flakes of carbon are evident, and it is clear that the CoPC-SPCE has a porous, three dimensional structure; image (ii) was taken after the deposition of LOX, followed by a drying step; the enzyme layer is dispersed evenly in discrete structures; image (iii) was obtained after the deposition of a glutaraldehyde layer on top of the enzyme layer, followed by a drying/cross linking step. This latter step results in a cohesive coating that was considered to strongly immobilise the enzyme onto the SPCE-CoPC surface. At the stage, we considered that the biosensor should be suitable for our proposed method of operation, for fatty acid analysis, involving amperometry in stirred solution. This is discussed in the following section. 


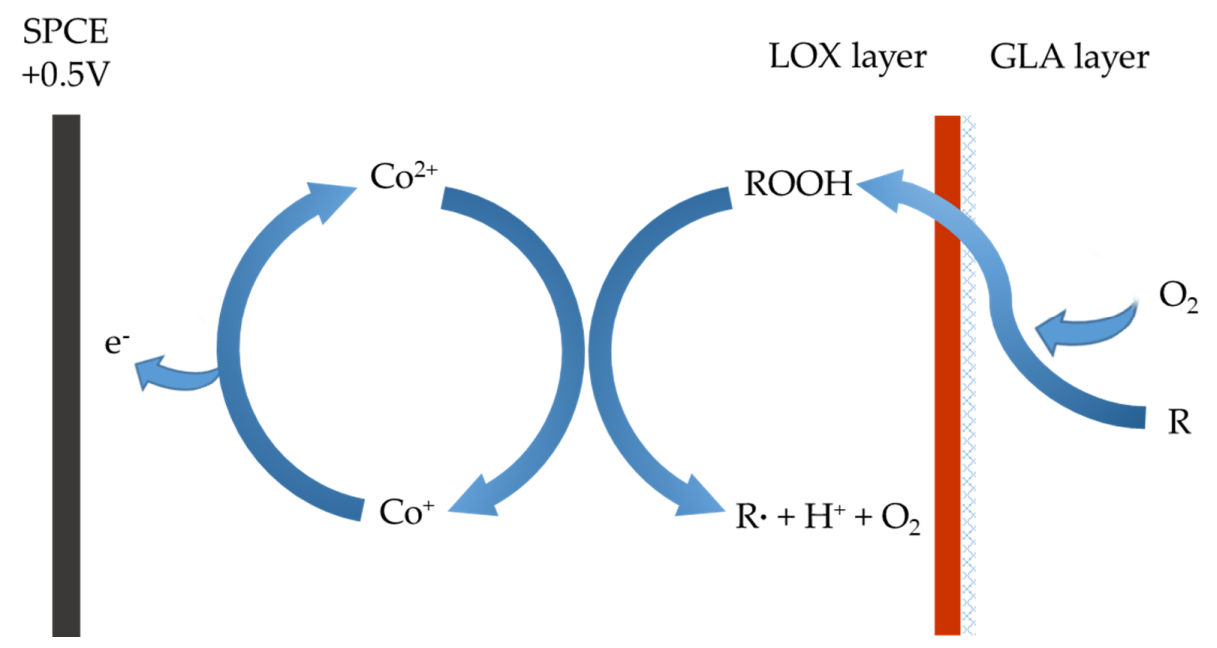

Figure 3. Schematic diagram of the amperometric fatty acid biosensor design and the sequence of reactions involved in its operation; SPCE = screen-printed carbon electrode; LOX = lipoxygenase; GLA = glutaraldehyde.

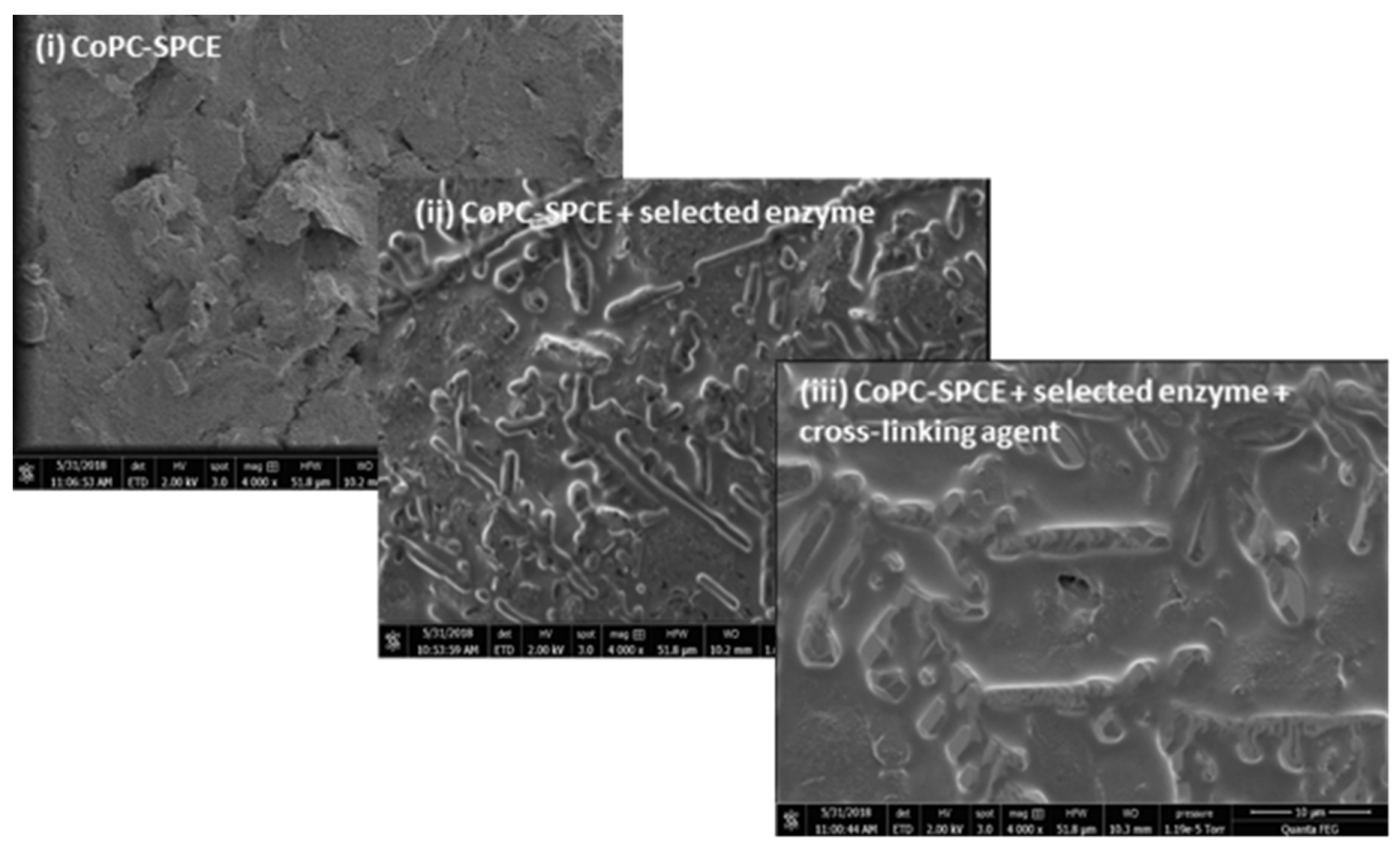

Figure 4. Scanning electron microscopy images obtained of the working electrodes of: (i) initial cobalt phthalocyanine screen-printed carbon electrode (COPC-SPCE); (ii) CoPC-SPCE with lipoxygenase (LOX) deposited on the surface; (iii) COPC-SPCE with LOX and glutaraldehyde deposited on the surface.

3.3. Optimisation of Applied Potential and Other Conditions Using Amperometry in Stirred Solution and Calibration Studies with Linoleic and $\alpha$-Linolenic Acids

In order to deduce the optimum potential for the operation of the biosensor, hydrodynamic voltammograms (HDVs) were constructed for solutions containing either linoleic acid, or $\alpha$-linolenic acid.

To construct these HDVs, the biosensor was placed in a stirred solution of the selected fatty acid and left for $600 \mathrm{~s}$ at open circuit; the potential was then stepped between $0 \mathrm{~V}$ and $+1.0 \mathrm{~V}$ (vs. $\mathrm{Ag} / \mathrm{AgCl}$ ), in $50 \mathrm{mV}$ steps. After each change in potential, the steady state currents were measured after a waiting time of $600 \mathrm{~s}$. These currents were then plotted against the corresponding applied potential to produce the HDV (Figure 5). Clearly, both compounds exhibited one well-defined voltammetric response, 
which concurs with that found earlier in our cyclic voltammetric study (Figure 1). From the position of the plateau, we deduced that the optimum operating potential for both fatty acids was $+0.5 \mathrm{~V}$ (vs. $\mathrm{Ag} / \mathrm{AgCl}$ ). It should be noted that this potential is less positive than that seen in Figure 1; this is probably due to the cyclic voltammetric responses being directly related to scan rate [21], and as our HDVs are obtained with a very low scan rate $(0.083 \mathrm{mV} / \mathrm{s})$, the oxidative responses occur at lower applied potentials.

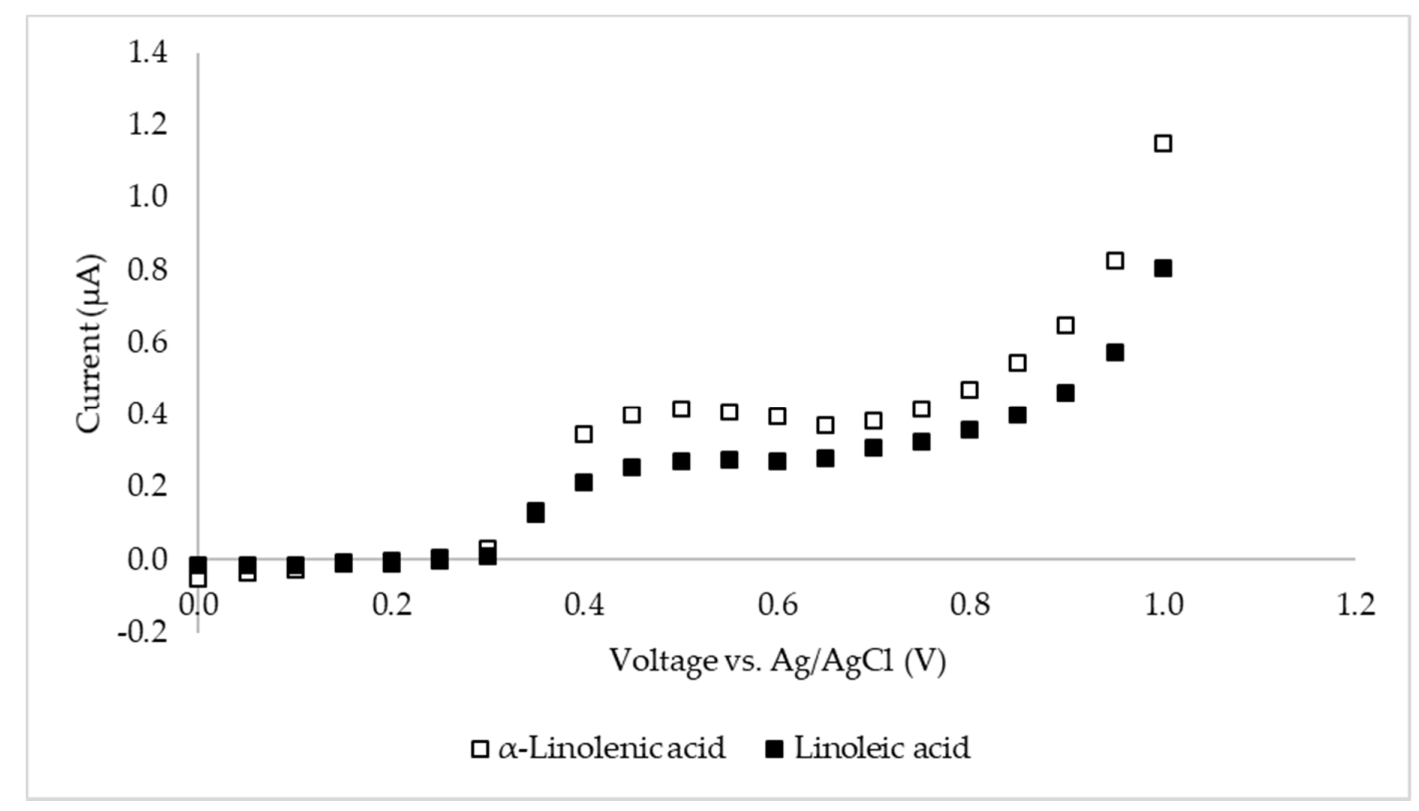

Figure 5. Hydrodynamic voltammograms obtained for: (white) $\alpha$-linolenic acid and (black) linoleic acid both a concentration of $100 \mu \mathrm{M}$; the supporting electrolyte consisted of $0.1 \mathrm{M}$ phosphate buffer $\mathrm{pH} 7.0$ containing $0.1 \mathrm{M} \mathrm{NaCl}$, using a cobalt phthalocyanine screen-printed carbon electrode with 15,000 units of lipoxygenase.

\subsection{Effect of Enzyme Loading}

Biosensors were prepared in the manner described earlier (see biosensor fabrication and storage) with the enzyme LOX at loadings of 15 to 15,000 units per biosensor. These biosensors were initially investigated with solutions of linoleic acid over the concentration range 20 to $200 \mu \mathrm{M}$, using a supporting electrolyte solution comprised of PBS pH 7.0, at a fixed temperature of $37^{\circ} \mathrm{C}$. Calibration graphs were constructed and it was shown that these plots were non-linear, exhibiting Michaelis Menten type behaviour. For all loadings studied the greatest change in steady state current occurred between 20-100 $\mu \mathrm{M}$, this was followed by a gradual increase to $200 \mu \mathrm{M}$. For comparison, the steady state currents were measured at $100 \mu \mathrm{M}$ and the following values were obtained: $0.903 \mu \mathrm{A}$ for 15 units of LOX; $0.471 \mu \mathrm{A}$ for 150 units of LOX; $0.306 \mu \mathrm{A}$ for 1500 units of LOX; $0.095 \mu \mathrm{A}$ for 15,000 units of LOX. The decrease in sensitivity with increase in loading is probably due to a decrease in the rate of diffusion of the fatty acid through the outer reaction layer, and lower diffusion rate of the hydroperoxide produced in this layer, towards the CoPC-SPCE surface.

As we wanted our biosensor to have a high sensitivity for trace FFA determinations, we selected $15 \mathrm{U}$ to study concentrations between 2 and $20 \mu \mathrm{M}$, at the same $\mathrm{pH}$ and temperature as above. We found that the response for this un-optimised biosensor was linear between 2 and $10 \mu \mathrm{M}$ and the sensitivity was $0.0085 \mu \mathrm{A} \mu \mathrm{M}-1$. We also carried a similar study with $\alpha$-linolenic acid and the linear range and sensitivity were found to be 2 to $20 \mu \mathrm{M}$ and $0.0111 \mu \mathrm{A} / \mu \mathrm{M}$, respectively. These initial studies were encouraging and demonstrated the possibility of measuring low concentrations of both linoleic and $\alpha$-linolenic acid. Having deduced the optimum enzyme loading, further studies were next performed to further optimise the biosensor performance and these are discussed in the following sections. 


\subsection{Effect of $p H$}

Calibration studies were performed using the proposed biosensors in conjunction with constant potential amperometry in stirred solution; studies were carried out with both fatty acids over the concentration range 2 to $20 \mu \mathrm{M}$, between $\mathrm{pH}$ values of $\mathrm{pH} 6.0$ to $\mathrm{pH} 9.0$. The resulting calibration plots were then used to deduce the sensitivities and linear ranges for both linoleic acid and $\alpha$-linolenic acid using these conditions (Table 1).

Table 1. Slopes and linear ranges of $\alpha$-linolenic and linoleic acid at $25^{\circ} \mathrm{C}$ and $\mathrm{pH} 6.0,7,8.0$ and 9.0.

\begin{tabular}{cccc}
\hline Fatty Acid & $\mathbf{p H}$ & Slope $(\mu \mathrm{A} / \mu \mathbf{M})$ & Linear Range $(\mu \mathbf{M})$ \\
\hline \multirow{3}{*}{$\alpha$-Linolenic acid } & 6 & 0.005 & 2 to 6 \\
& 8 & 0.006 & 2 to 10 \\
& 9 & 0.009 & 2 to 10 \\
Linoleic acid & 6 & 0.009 & 2 to 10 \\
& 8 & 0.003 & 2 to 6 \\
& 9 & 0.009 & 2 to 10 \\
& 9 & 0.014 & 2 to 10 \\
\end{tabular}

For linoleic acid, $\mathrm{pH} 8$ appears to offer the best sensitivity $\left(0.014 \mu \mathrm{AmM}^{-1}\right)$, whereas the linear range was the same for $\mathrm{pH}$ values between 7 to $9(2$ to $10 \mu \mathrm{M})$. For $\alpha$-linolenic acid, it would appear that $\mathrm{pH} 8$ and 9 offer the best sensitivity $\left(0.009 \mu \mathrm{AmM}^{-1}\right.$ for both) and linear range (2 to $10 \mu \mathrm{M}$ for both). This study led us to choose a phosphate buffer of $\mathrm{pH} 8$ containing $0.1 \mathrm{M}$ sodium chloride for all further studies.

\subsection{Effect of Temperature}

Calibration studies were performed with the same biosensors as mentioned earlier, over the temperature range $25^{\circ} \mathrm{C}$ to $40^{\circ} \mathrm{C}$, with fatty acid concentrations between 2 to $20 \mu \mathrm{M}$ (Table 2); these were achieved with a buffer solution $\mathrm{pH} 8$ and with 15 units of LOX.

Table 2. Slopes and linear ranges of $\alpha$-linolenic and linoleic acid at $\mathrm{pH} 8.0$ and 25, 30, 37 and $40{ }^{\circ} \mathrm{C}$.

\begin{tabular}{cccc}
\hline Fatty Acid & Temperature $\left({ }^{\circ} \mathbf{C}\right)$ & Slope $(\mu \mathbf{A} / \mu \mathbf{M})$ & Linear Range $(\boldsymbol{\mu M})$ \\
\hline \multirow{3}{*}{$\alpha$-Linolenic } & 25 & 0.008 & 2 to 10 \\
& 30 & 0.013 & 2 to 8 \\
& 37 & 0.017 & 2 to 10 \\
Linoleic acid & 40 & 0.021 & 2 to 8 \\
\hline \multirow{3}{*}{} & 25 & 0.010 & 2 to 10 \\
& 30 & 0.012 & 2 to 10 \\
& 37 & 0.021 & 2 to 10 \\
& 40 & 0.017 & 2 to 10 \\
\hline
\end{tabular}

The highest sensitivity for linoleic acid was achieved using a temperature of $37^{\circ} \mathrm{C}$ whereas $\alpha$-linolenic acid showed slightly greater sensitivity at $40{ }^{\circ} \mathrm{C}$; however, the linear range was better at $37^{\circ} \mathrm{C}$. At this temperature the linear range for both compounds was 2 to $10 \mu \mathrm{M}$.

As we wished to ascertain the ability of the devices to measure the trace concentrations likely to be present in food safety situations, we next carried out calibration studies using lower concentrations $(0.2$ to $2 \mu \mathrm{M})$ of the two fatty acids.

Figure 6 shows the amperometric responses over the lower concentration range studied. Clearly, well defined responses were achieved down to $0.2 \mu \mathrm{M}$ and the detection limit obtained at a signal to noise ratio of 3:1 was $24 \mathrm{nM}$. 


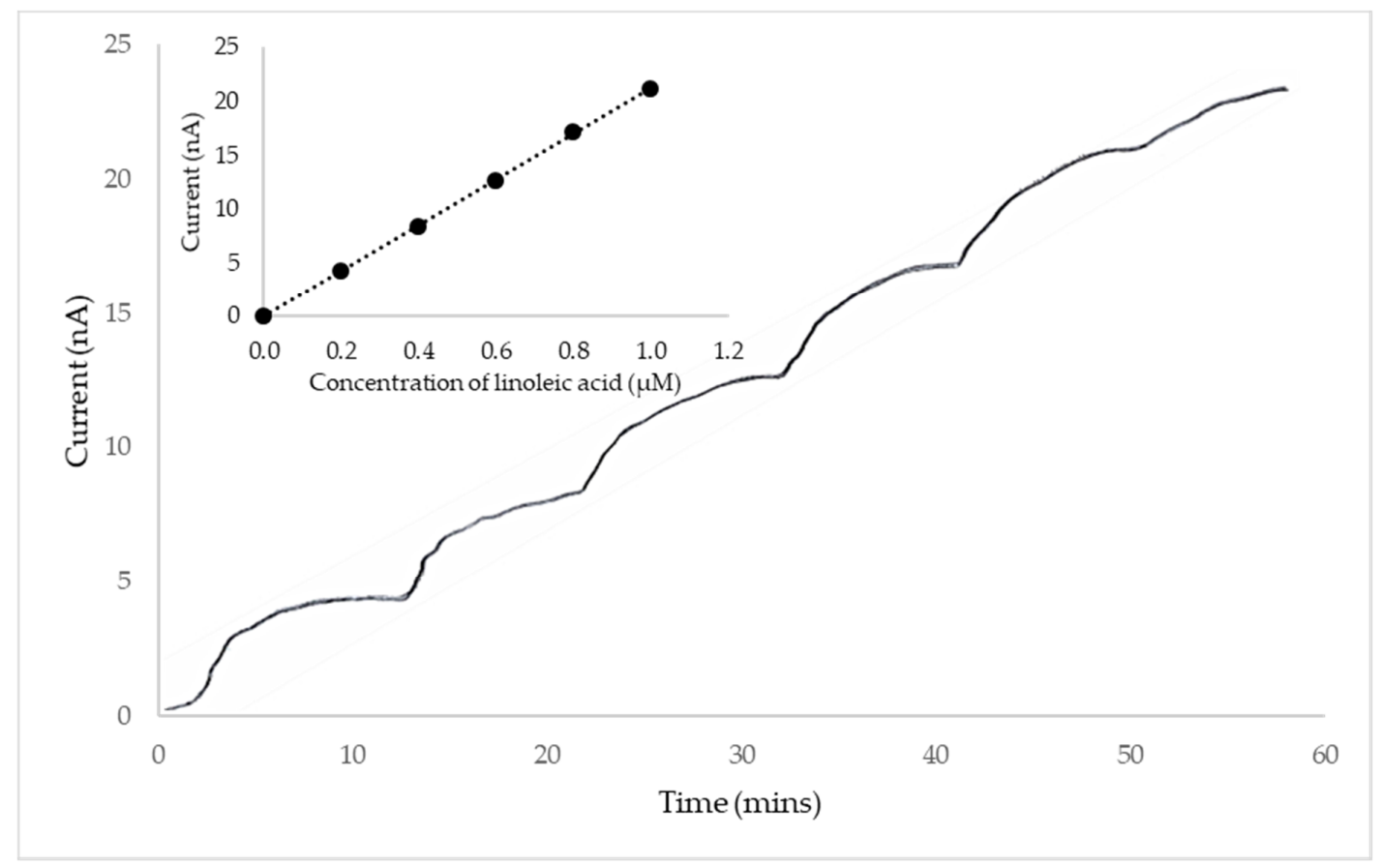

Figure 6. Amperometric responses at a cobalt phthalocyanine screen-printed carbon electrode with 15 units of lipoxygenase, obtained following 5 additions of $0.2 \mu \mathrm{M}$ linoleic acid, with standard addition plot (insert).

\section{Conclusions}

In this paper, we have successfully demonstrated the fabrication and operation of a novel amperometric screen printed biosensor for the measurement of linoleic and $\alpha$-linoleic acid down to 24 and $100 \mathrm{nM}$, respectively. This is mainly due to electrocatalytic responses of hydroperoxides of the PUFAs, produced by LOX; the oxidation potentials of these species occur at much lower values than obtained by direct oxidation at plain SPCEs.

The fabrication method is convenient and inexpensive; it requires only deposition of an enzyme (LOX) and glutaraldehyde layer onto the surface of a CoPC-SPCE. These single use, disposable biosensors are used in conjunction with amperometry in stirred solution, which is simple to perform and easy to interpret, thus suitable for use by non-technical personnel. The response is proportional to concentration across a wide range, and linear from 0.2 to $10 \mu \mathrm{M}$, thus has potential for measurement FFAs for food safety and quality purposes.

It should be mentioned that, in addition to CoPC, other cobalt species have been successfully employed as the basis of electrocatalytic amperometric (bio)sensors. For example, Florescu et al. [22] successfully developed an amperometric biosensor based on cobalt hexacyanoferate for glucose determination using modified carbon film electrodes with glucose oxidase; Lang et al. [23] developed an enzyme-less amperometric sensor based on cobalt oxide nanoparticles for the measurement of glucose, achieving detection limits down to $5 \mathrm{nM}$ and cobalt chloride was immobilised on a glassy carbon electrode using chitosan and MWCNTs by Akhter et al. [24] for paracetamol determination. However, to our knowledge, none of these cobalt species have been investigated or employed in sensors for fatty acid analysis.

The performance of our biosensor compares favourably to other electrochemical approaches for measuring unsaturated FFAs (Table 3). Jerkovic et al. (2018) [3] used a cobalt phthalocyanine (CoPC) mediated carbon paste electrode to measure linoleic acid in safflower oil. The linear range was 7.5 to $200 \mu \mathrm{g} / \mathrm{mL}$ and the detection limit was $2.5 \mu \mathrm{g} / \mathrm{mL}$. Schoemaker et al. developed an amperometric biosensor containing LOX, for the measurement of linoleic and $\alpha$-linoleic acid in fats and oils, using an 
oxygen electrode as the base transducer [25]. The detection limits were 7.7 and $4.8 \mu \mathrm{M}$, respectively, with a linear range of 0.01 to $0.2 \mathrm{mM}$ for both fatty acids.

Table 3. Electrochemical approaches for measuring unsaturated fatty acids.

\begin{tabular}{|c|c|c|c|c|c|}
\hline Biosensor/Sensor & Fatty Acids(s) & $\begin{array}{l}\text { Limit of } \\
\text { Detection }\end{array}$ & Linear Range & $\begin{array}{c}\text { Potential for } \\
\text { Commercial-Isation? }\end{array}$ & Reference \\
\hline $\begin{array}{l}\text { CoPC-SPCE with } \\
\text { LOX }\end{array}$ & $\begin{array}{l}\alpha \text {-Linolenic acid; } \\
\text { linoleic acid }\end{array}$ & $100 \mathrm{nM} ; 24 \mathrm{nM}$ & $\begin{array}{l}0.2 \text { to } 10 \mu \mathrm{M} \\
\quad \text { for both }\end{array}$ & Yes & Smart et al., 2020 \\
\hline $\begin{array}{l}\text { CoPC carbon paste } \\
\text { electrode }\end{array}$ & Linoleic acid & $2.5 \mu \mathrm{g} / \mathrm{ml}$ & 7.5 to $200 \mu \mathrm{g} / \mathrm{ml}$ & No & Jerkovic et al., 2018 [3] \\
\hline $\begin{array}{l}\text { Screen printed } \\
\text { graphene oxide } \\
\text { electrode with LOX } \\
\text { and ruthenium }\end{array}$ & Oleic acid & $<0.1 \mathrm{mM}$ & 0.1 to $1.0 \mathrm{mM}$ & Yes & $\begin{array}{l}\text { Veerpandian et al., } \\
2017 \text { [26] }\end{array}$ \\
\hline $\begin{array}{l}\text { Oxygen electrode } \\
\text { with LOX }\end{array}$ & $\begin{array}{l}\alpha \text {-Linolenic acid } \\
\text { linoleic acid }\end{array}$ & $4.8 \mu \mathrm{M} ; 7.7 \mu \mathrm{M}$ & $\begin{array}{l}0.02 \text { to } 0.2 \mathrm{mM} \\
\quad \text { for both }\end{array}$ & No & $\begin{array}{c}\text { Schoemaker et al., } \\
1997 \text { [25] }\end{array}$ \\
\hline
\end{tabular}

CoPC-SPCE = cobalt phthalocyanine screen-printed carbon electrode; LOX = lipoxygenase.

Jerkovic's method did not include an enzyme, and was only able to measure a single PUFA. Carbon paste and oxygen electrodes also problematic for commercialisation. For commercialisation purposes biosensors need to be mass produced at low cost. Veerpandian et al. [26] used a screen printed graphene oxide biosensor containing LOX and ruthenium electrocatalyst to measure the monounsaturated fatty acid oleic acid in calf serum. The detection limit was $<0.1 \mathrm{mM}$, and the linear range was 0.1 to $1.0 \mathrm{mM}$. The authors claim it is very selective for oleic acid, which has a different reaction mechanism with LOX than PUFAs, which were not measured.

We believe that our approach offers a real possibility of achieving a commercial device for the measurement of PUFAs; future work will investigate the application this novel biosesnsor to food samples.

Author Contributions: Conceptualization, A.S., A.C., O.D. and J.P.H.; formal analysis, A.S., A.C., O.D. and J.P.H.; funding acquisition, A.S., A.C., O.D. and J.P.H.; investigation, A.S., A.C., O.D. and J.P.H.; methodology, A.S., A.C., O.D. and J.P.H.; project administration, A.S., A.C., O.D. and J.P.H.; supervision, A.S., A.C., O.D. and J.P.H.; validation, A.S., A.C., O.D. and J.P.H.; visualization, A.S., A.C., O.D. and J.P.H.; writing-original draft preparation, A.S., A.C., O.D. and J.P.H.; writing-review and editing, A.S., A.C., O.D. and J.P.H. All authors have read and agreed to the published version of the manuscript.

Funding: This project was funded by the Agriculture and Horticulture Development Board (AHDB); A.S. is a recipient of an AHDB PhD studentship.

Acknowledgments: The authors would like to thank the University of the West of England (UWE) Bristol for support and the Agricultural Horticultural Development Board (AHDB) for funding. They are grateful to Gwent Electronic Materials Ltd. part of the Sun Chemical Corporation for supplying the screen-printed carbon electrodes. They would also like to thank David Patton (University of the West of England, Bristol) for his help in obtaining the scanning electron microscope images.

Conflicts of Interest: The authors declare no conflict of interest.

\section{Abbreviations}

$\begin{array}{ll}\text { Abbreviation } & \text { Definition } \\ \text { PUFA } & \text { Polyunsaturated fatty acid } \\ \text { SPCE } & \text { Screen-printed carbon electrode } \\ \text { CoPC } & \text { Cobalt phthalocyanine } \\ \text { LOX } & \text { Lipoxygenase } \\ \text { FFA } & \text { Free fatty acid } \\ \text { HDV } & \text { Hydrodynamic voltammogram }\end{array}$

\section{References}

1. Willett, W.C. Dietary fats and coronary heart disease. J. Intern. Med. 2012, 272, 13-24. [CrossRef] 
2. Jong, J.C.K.-D.; Mathers, J.C.; Franco, O.H. Nutrition and healthy ageing: The key ingredients. Proc. Nutr. Soc. 2014, 73, 249-259. [CrossRef] [PubMed]

3. Jerković, A.; Abou-Ahmed, S.; Ertl, P.; Stoeßl, B.; Lengauer, V.; Samphao, A.; Kalcher, K.; Leitinger, G.; Wernitznig, S.; Ortner, A. Development of a cobalt(II) phthalocyanine- MWCNT modified carbon paste electrode for the detection of polyunsaturated fatty acids. Anal. Chim. Acta 2018, 1038, 52-58. [CrossRef] [PubMed]

4. Mahesar, S.A.; Sherazi, S.T.H.; Khaskheli, A.R.; Kandhro, A.A.; Uddin, S. Analytical approaches for the assessment of free fatty acids in oils and fats. Anal. Methods 2014, 6, 4956-4963. [CrossRef]

5. Wiking, L.; Løkke, M.; Kidmose, U.; Sundekilde, U.K.; Dalsgaard, T.; Larsen, T.; Feilberg, A. Comparison between novel and standard methods for analysis of free fatty acids in milk-Including relation to rancid flavour. Int. Dairy J. 2017, 75, 22-29. [CrossRef]

6. Dos Santos, M.V.; Ma, Y.; Caplan, Z.; Barbano, D. Sensory Threshold of Off-Flavors Caused by Proteolysis and Lipolysis in Milk. J. Dairy Sci. 2003, 86, 1601-1607. [CrossRef]

7. González-Córdova, A.F.; Vallejo-Cordoba, B. Detection and Prediction of Hydrolytic Rancidity in Milk by Multiple Regression Analysis of Short-Chain Free Fatty Acids Determined by Solid Phase Microextraction Gas Chromatography and Quantitative Flavor Intensity Assessment. J. Agric. Food Chem. 2003, 51, 7127-7131. [CrossRef] [PubMed]

8. Muik, B.; Lendl, B.; Molina-Díaz, A.; Ayora-Cañada, M.J. Direct, reagent-free determination of free fatty acid content in olive oil and olives by Fourier transform Raman spectrometry. Anal. Chim. Acta 2003, 487, 211-220. [CrossRef]

9. Dand, R. The International Cocoa Trade, 3rd ed.; Woodhead Publishing Limited: Cambridge, UK, 2011; pp. 219-267.

10. Smart, A.; Crew, A.; Pemberton, R.; Hughes, G.; Doran, O.; Hart, J. Screen-printed carbon based biosensors and their applications in agri-food safety. TrAC Trends Anal. Chem. 2020, 127, 115898. [CrossRef]

11. Pemberton, R.M.; Hart, J.P.; Mottram, T.T. An electrochemical immunosensor for milk progesterone using a continuous flow system. Biosens. Bioelectron. 2001, 16, 715-723. [CrossRef]

12. Hughes, G.; Pemberton, R.; Fielden, P.; Hart, J.P. Development of a disposable screen-printed amperometric biosensor based on glutamate dehydrogenase, for the determination of glutamate in clinical and food applications. Anal. Bioanal. Electrochem. 2014, 6, 435-449.

13. Nicholas, P.; Pittson, R.; Hart, J. Development of a simple, low cost chronoamperometric assay for fructose based on a commercial graphite-nanoparticle modified screen-printed carbon electrode. Food Chem. 2018, 241, 122-126. [CrossRef]

14. Crew, A.; Hart, J.P.; Wedge, R.; Marty, J.L.; Fournier, D. A Screen-Printed, Amperometric, Biosensor Array for the Detection of Organophosphate Pesticides Based on Inhibition of Wild Type, and Mutant Acetylcholinesterases, fromDrosophila melanogaster. Anal. Lett. 2004, 37, 1601-1610. [CrossRef]

15. Westmacott, K.; Crew, A.; Doran, O.; Hart, J. Novel, rapid, low-cost screen-printed (bio)sensors for the direct analysis of boar taint compounds androstenone and skatole in porcine adipose tissue: Comparison with a high-resolution gas chromatographic method. Biosens. Bioelectron. 2020, 150, 111837. [CrossRef]

16. Smart, A.; Westmacott, K.L.; Crew, A.; Doran, O.; Hart, J.P. An Electrocatalytic Screen-Printed Amperometric Sensor for the Selective Measurement of Thiamine (Vitamin B1) in Food Supplements. Biosens. Bioelectron. 2019, 9, 98. [CrossRef] [PubMed]

17. Gardner, H.W.; Weisleder, D. Hydroperoxides from oxidation of linoleic and linolenic acids by soybean lipoxygenase: Proof of thetrans-11 double bond. Lipids 1972, 7, 191-193. [CrossRef]

18. Gilmartin, M.A.T.; Ewen, R.J.; Hart, J.P.; Honeybourne, C.L. Voltammetric and photoelectron spectral elucidation of the electrocatalytic oxidation of hydrogen peroxide at screen-printed carbon electrodes chemically modified with cobalt phthalocyanine. Electroanalysis 1995, 7, 547-555. [CrossRef]

19. Ballarin, B.; Gazzano, M.; De Cisneros, J.H.H.; Tonelli, D.; Seeber, R. Electrocatalytic activity of cobalt phthalocyanine stabilized by different matrixes. Anal. Bioanal. Chem. 2002, 374, 891-897. [PubMed]

20. Crouch, E.; Cowell, D.C.; Hoskins, S.; Pittson, R.W.; Hart, J. A novel, disposable, screen-printed amperometric biosensor for glucose in serum fabricated using a water-based carbon ink. Biosens. Bioelectron. 2005, 21, 712-718. [CrossRef]

21. Pletcher, D.; Greff, R.; Peat, R.; Peter, L.M.; Robinson, J. Instrumental Methods in Electrochemistry, 2nd ed.; Ellis Horwood Limited: Cambridge, UK, 1990; p. 187. 
22. Florescu, M.; Brett, C.M. Development and Characterization of Cobalt Hexacyanoferrate Modified Carbon Electrodes for Electrochemical Enzyme Biosensors. Anal. Lett. 2004, 37, 871-886. [CrossRef]

23. Lang, X.-Y.; Fu, H.-Y.; Hou, C.; Han, G.-F.; Yang, P.; Liu, Y.-B.; Jiang, Q. Nanoporous gold supported cobalt oxide microelectrodes as high-performance electrochemical biosensors. Nat. Commun. 2013, 4, 2169. [CrossRef]

24. Akhter, S.; Basirun, W.J.; Alias, Y.; Johan, M.R.; Bagheri, S.; Shalauddin, M.; Ladan, M.; Anuar, N.S. Enhanced amperometric detection of paracetamol by immobilized cobalt ion on functionalized MWCNTs-Chitosan thin film. Anal. Biochem. 2018, 551, 29-36. [CrossRef] [PubMed]

25. Schoemaker, M.; Feldbrügge, R.; Gründig, B.; Spener, F. The lipoxygenase sensor, a new approach in essential fatty acid determination in foods. Biosens. Bioelectron. 1997, 12, 1089-1099. [CrossRef]

26. Veerapandian, M.; Hunter, R.; Neethirajan, S. Lipoxygenase-modified Ru-bpy/graphene oxide: Electrochemical biosensor for on-farm monitoring of non-esterified fatty acid. Biosens. Bioelectron. 2016, 78, 253-258. [CrossRef]

Publisher's Note: MDPI stays neutral with regard to jurisdictional claims in published maps and institutional affiliations.

(C) 2020 by the authors. Licensee MDPI, Basel, Switzerland. This article is an open access article distributed under the terms and conditions of the Creative Commons Attribution (CC BY) license (http://creativecommons.org/licenses/by/4.0/). 